\title{
Depth Distribution of the Electric Conductivity on the Czechoslovak Territory
}

\author{
J. P̌̌Čová, V. Petr and O. Praus \\ Geophysical Institute of Czechosl. Acad. Sci., Prague
}

(Received January 12, 1970)

\begin{abstract}
Results of magnetotelluric soundings have been obtained for a series of five field stations located approximately along the international profile of deep seismic sounding No. VI. Multilayer sounding curves at almost all stations show anisotropic and/or horizontally non-homogeneous situation. Methods for estimating the inhomogeneity measures were applied and attempts have been made to locate the homogeneity axis and corresponding two-dimensional structures. Directional properties of the electric conductivity have been discussed and fitted to the local geology.

On respecting the uncertainty and ambiguity of apparent resistivity curves the depths of remarkable discontinuities have been estimated and traced along the profile.
\end{abstract}

The study of peculiarities in the distribution of the electric conductivity within the Earth's crust and in the upper mantle has been carried out as a special contribution to the Czechoslovak program of the UMP. The research program involves the estimates of the electric conductivity variation as a function of the depth below the Earthś surface from the observations of electromagnetic field variations.

The data recorded at permanent observatories Budkov and Hurbanovo-Srobárová were first used in estimating the depth distribution of the electric conductivity. These data were then supplemented by magnetotelluric measurements at a series of field stations situated approximately along the international profile of deep seismic sounding No. VI. The locations and the profile of the field stations are shown in Fig. 1. This profile, running from SE to NW on Czechoslovak territory, crosses geological formations of different ages and of different structures. Magnetotelluric data have been obtained, thus, under different conditions characterized by the presence of a thick, relatively conductive sedimentary layer, on the one hand and, on the other hand, by the presence of only a thin layer of conductive materials or even by their absence at the surface of cristallinic high-resistive blocks.

Five field components of the magnetotelluric field ( 3 magnetic +2 horizontal electric) were recorded continuously at each station for the period of two months at least. Two recording sets were used to obtain variation data in the range of periods from a few seconds to a few hours.

The experimental data were processed by direct reading of the amplitudes of the quasisinusoidal variations such as PC 1 and PC 3, or, by applying the methods of spectral 


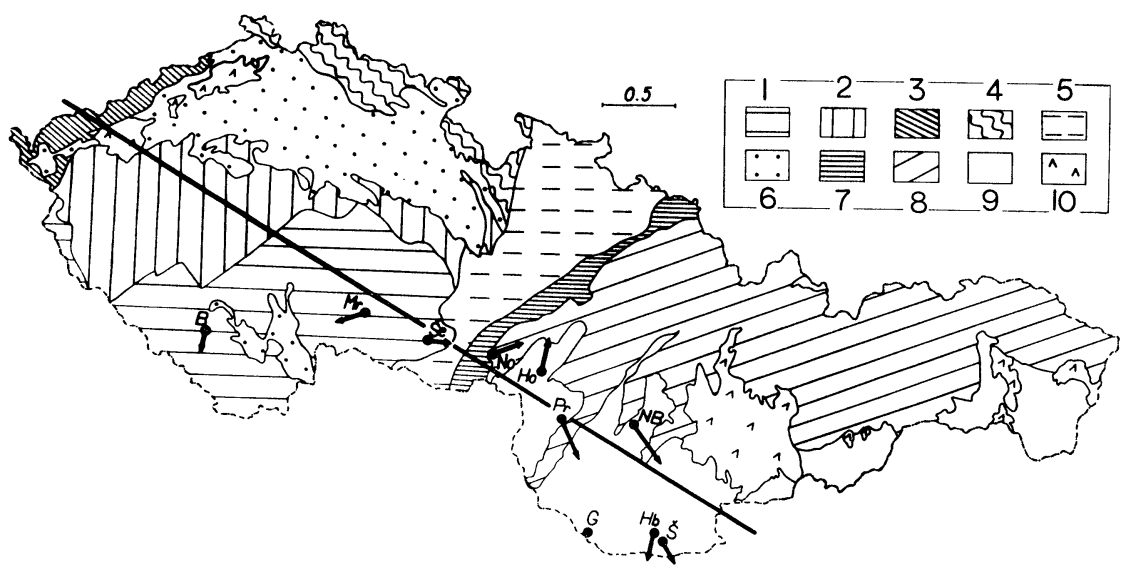

Fig. 1. Geological map of Czechoslovakia with profile No. VI of DSS, location of field stations and induction vectors. Symbols for the stations : Š-Srobárová, HbHurbanovo, G-Gabčíkovo, NB-Nitrianská Blatnica, Pr-Prievaly, Ho-Hodonín, No-Nosislav, Še-Šemíkovice, Mr-Mrákotín, B-Bubkov. Value 0.5 gives a measure for $|\mathrm{C}|$. Czech Massif : 1. Moldanubian block, 2. Assyntian block, 3. ThuringiaSaxonian block, 4. West Sudeten block, 5. Moravian-Silesian zone, 6. Cretaceous and Tertiary platform deposits. 7. Alpine-Carpathian fore-deep. Carpathian region : 8. Pre-Neogene folding of the Carpathian unit, 9. Neogene basin of the Carpathian region, 10. Tertiary eruptive rocks.

analysis to the variations of a general form. From amplitudes, or maximum peaks of spectral density curves the ratios $E_{x} / H_{y}$ and $E_{y} / H_{x}$, i. e. the apparent impedances, were calculated and represented as plots against $\sqrt{ } \bar{T}$. The plots were smoothed and the resultant average impedances were used for calculating the apparent resistivity curves using the well known Tikhonow- Cagniard formulae. Magnetotelluric curves from different stations are compiled in Fig. 2 [1-5].

The magnetotelluric curves obtained show the apparent resistivity to be a complex function of the depth and, moreover, they show that the Earth is not consistent with a model of a stratified isotropic medium. The apparent resistivity curves at almost all stations are shifted with respect to each other over the whole range of periods, or at least, for a limited range of periods. The explanation for this fact has to be sought in the lateral variations of the conductivity and in large scale inhomogeneities of the medium. In that case the interpretation involves many unknown facts because the information on the electric properties is distributed in an unknown way among four components of the second order impedance tensor.

Analysis of that type involves extensive computer work which are now under way. The procedure includes the calculation of the impedance tensor elements, the numerical rotation of the coordinate system and the location of the principal directions in which the impedance tensor reduces to two non-zero principal elements. This procedure is equivalent to finding a two-dimensional structure with a certain homogeneity axis along which the geoelectric properties of the medium do not change substantially.

For the preliminary interpretation, we are dealing with in this report, we have estima- 


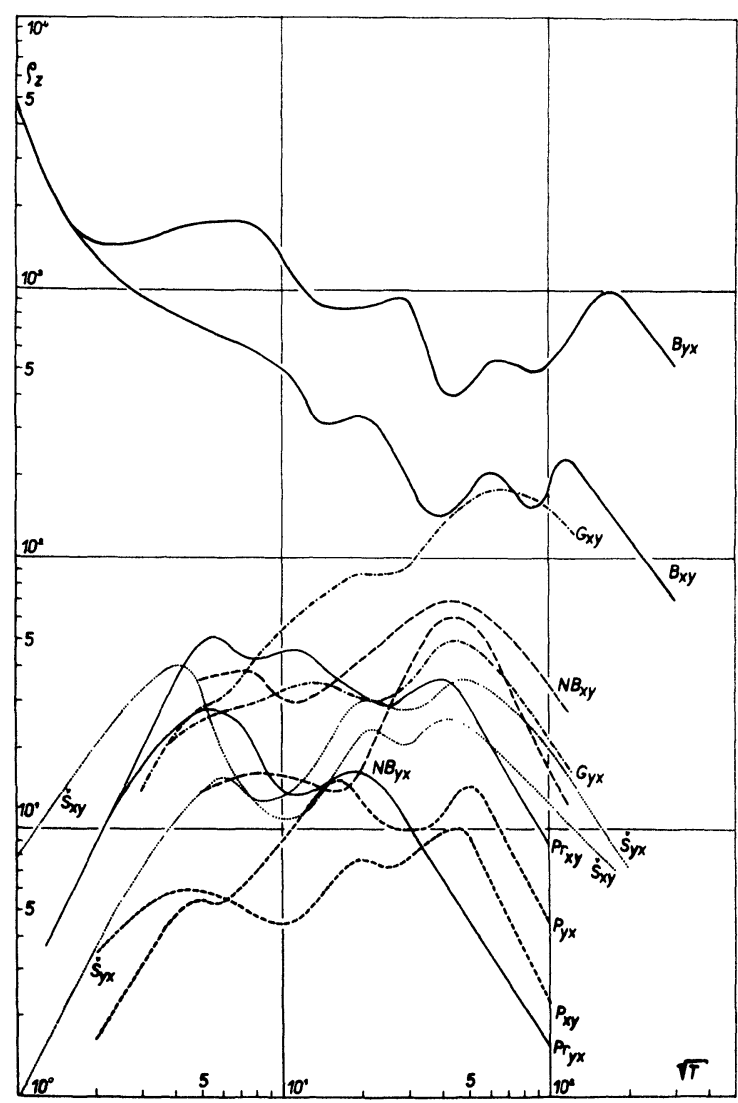

Fig. 2. Magnetotelluric sounding curves $\rho_{Z X}=$ $f_{1}(\sqrt{T})$ and $\rho_{Z Y}=f_{2}(\sqrt{T})$ for the stations on Czechoslovak territory. ted the inhomogeneity of the medium and the principal directions of a possible two-dimensional structure by applying the approximate methods of the Wiese vector and the Rokityanski analysis.

The method of the Wiese vector uses the relation between the Z-component of the geomagnetic field and both the horizontal components. The length and the direction of the vector involve the information about the local distribution of the electric conductivity. In estimating the inhomogeneity measure we kept in mind the theoretical principle that zero or very small values of the induction vector are to be expected over a horizontally stratified area if, at the same time, small values and similar directions are found in a sufficiently large neighbourhood of the station, or, on the contrary, just above the zone of a strong inhomogeneity, if large values of the vector and large changes

of its direction are observed in the proximity of a station.

The induction vectors are shown as oriented arrows for all stations analysed so far (Fig. 1). Numerical characteristics of the vectors are summarized in Tab. 1 (amplitude $|\mathrm{C}|$ and azimuth $\left.\theta^{\circ} \mathrm{E}\right)$.

The anisotropy axes were determined by Rokityanski's method based on the polarization properties of the magnetotelluric field [6]. Both the principal direction of the axes and the anisotropy coefficient were estimated. The results for the azimuths of the anisotropy axes were stable for a given station and they are summarized in Tab. 1. The numerical measure of the anisotropy, however, increased rapidly with the variation period by more than one decimal order and a large scatter was usually observed. We think the method is not reliable enough for estimating the numerical magnitude of the anisotropy and, therefore, the values were not included into Tab. 1.

Two regions with different characteristics are clearly identified from the vector distribution and azimuths of anisotropy axes. According to our results and respecting previous results of Wiese as well [7] we find a fairly homogeneous distribution of relatively small vectors in the SE part of the profile and their directions coincide well with the azimuths 
Table 1. Results of electromagnetic observation in Czechoslovakia.

\begin{tabular}{|c|c|c|c|c|c|c|c|c|}
\hline \multirow{3}{*}{$\begin{array}{c}\begin{array}{c}\text { Station } \\
\text { (Symbol) }\end{array} \\
\text { Šrobárová }(\check{\mathrm{S}})\end{array}$} & \multicolumn{2}{|c|}{ Induction vector } & \multicolumn{2}{|c|}{ Principal directions ${ }^{\circ} \mathrm{E}$} & \multirow{2}{*}{\multicolumn{4}{|c|}{$\begin{array}{l}\text { Layers of increased el. } \\
\text { conductivity-depth in } \mathrm{km}\end{array}$}} \\
\hline & \multirow{2}{*}{$\frac{|\mathrm{C}|}{0.183}$} & \multirow{2}{*}{$\frac{\theta^{\circ}}{163}$} & \multirow{2}{*}{$\frac{\text { Pulsations }}{128-150}$} & \multirow{2}{*}{$\frac{\text { Bays }}{135}$} & & & & \\
\hline & & & & & 1.5 & $11-15$ & 45 & 145 \\
\hline Hurbanovo (Hb) & 0.190 & 190 & - & 一 & - & - & - & - \\
\hline Gabčíkovo (G) & - & - & $125-138$ & 80 & 3.5 & 13 & 39 & 165 \\
\hline N. Blatnica (NB) & 0.314 & 143 & $39-45$ & 52 & ? & 20 & - & 200 \\
\hline Prievaly $(\mathrm{Pr})$ & 0.286 & 155 & $120-133$ & 92 & ? & 15 & 40 & 100 \\
\hline Hodonín (Ho) & 0.236 & 11 & $153-170$ & 203 & ? & 6 & 25 & $60-70$ \\
\hline Nosislav (No) & 0.204 & 67 & Not yet a & ised & - & 一 & - & - \\
\hline Šemíkovice (Še) & 0.129 & 94 & Not yet a & ised & ? & 10 & 35 & 250 \\
\hline Mrákotín (Mr) & 0.197 & 250 & Not yet a & ysed & - & - & - & - \\
\hline Budkov (B) & 0.125 & 199 & 25 & 36 & 0 & - & 25 & $\begin{array}{l}90-150 \\
350,800\end{array}$ \\
\hline
\end{tabular}

of the anisotropy axes obtained by Rokityanski's method. Consequently, the medium here seems to be almost horizontally homogeneous, or two-dimensional with a pronounced homogeneity axis approximately in the NE-SW direction. This conclusion seems to us only natural because the region belongs to the sedimentary basin of the Danube Lowlands and the homogeneity axis coincides with the main strike of the sedimentary basin.

A quite different situation was observed in the central section of the profile. The directions of the induction vectors at $\mathrm{NB}, \mathrm{Pr}, \mathrm{Ho}$, No, Še and $\mathrm{Mr}$ were subject to severe changes. Even two almost complete reversals of the vector directions were found between the pairs of stations Pr-Ho and Se-Mr. Also the anisotropy azimuths changed substantially between stations NB, Pr and Ho, and the directions did not coincide with those for the induction vector. This situation obviously indicates very complicated geologic conditions in this region. It represents a contact or transition zone in which the old Proterozoic Czech Massif submerges in a very complicated way beneath the Tertiary Alpine-Carpathian folded region. The geoelectric situation is expected to be very complicated with horizontally non-homogeneous conditions. The corresponding magnetotelluric curves must be treated with the greatest caution.

In treating the obtained magnetotelluric curves we can conveniently cathegorize them into the following groups :

1. Set of curves from stations with a rather thick sedimentary layer (over $2 \mathrm{~km}$ thick). They are represented by stations $\check{S}$ and $G$ from the sedimentary region of the Danube Lowlands and stations Pr and Ho which are located at the surface of a rather depression inside the Carpathian mountains called the Vienna basin.

2. Sounding at the surface of a non-conductive cristallinic block. This group is represented by the permanent station at Budkov which is situated at the surface of the Moldanubic block of the Czech Massif.

3. Transition type between those mentioned above is represented by the stations which are either near the boundary of the sedimentary basins (NB) or in the proximity of 
a contact of two different blocks ( $\mathrm{V} e$ near the contact zone between the Czech Massif with sediments of the Vienna basin).

Functions of the apparent resistivity can be explained by fitting a multilayered (5-7) model of the stratified medium. As regards the conclusions on the homogeneity measures the estimates for the depths of the probable discontinuities have been otained and summarized in Tab. 1. They indicate approximately the upper boundaries of the layers of increased electric conductivity. The conclusions from these data may be summarized in the following points:

1. Curves from Danube Lowlands $(\stackrel{V}{S}$ and $G)$ were fitted by a 7 layer model. The thickness of the sedimentary layer was estimated at $2.0-3.5 \mathrm{~km}$. The first layer of increased conductivity may be located at a depth of $11-15 \mathrm{~km}$. Further, there is an indication of a layer of increased conductivity at $40 \mathrm{~km}$ and finally the declining long period section of the curve may be explained by the presence of a conductive layer at a depth of $160 \mathrm{~km}$.

2. Slightly different depths were found at the station NB still belonging to the same sedimentary region. However, the station was situated near the boundary of the sedimentary basin. The first conductive layer was located here at $20 \mathrm{~km}$. The second layer was not found at all and the conductive layer in the upper mantle may be at a depth of $200 \mathrm{~km}$.

3. Curves from the sedimentary regions of the Vienna basin suggest different depths for the layers of increased conductivity. For the station at $\mathrm{Pr}$-in the proximity of the Carpathian mountains-the first layer was indicated at $15 \mathrm{~km}$ depth. At Ho station, however, the layer of increased conductivity seemed to be already at $6 \mathrm{~km}$. The second layer is located at $40 \mathrm{~km}$ at $\mathrm{Pr}$ and only $25 \mathrm{~km}$ at Ho. The layer of increased conductivity in the upper mantle seemed to be at $100 \mathrm{~km}$ at Pr but only at $60-70 \mathrm{~km}$ at Ho. These highly different depths of layers at stations which are only about $50 \mathrm{~km}$ apart seemed to us to be unrealistic. The discrepancy has to be accounted for the strong inhomogeneity of the medium suggested by the inversion of the Wiese vectors just between these stations. A detailed analysis of more data is required.

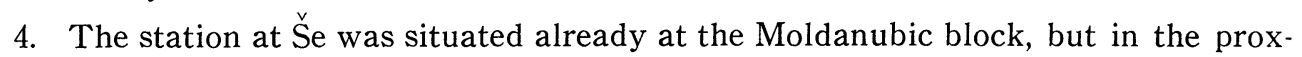
imity of the contact with the transition zone to the Carpathian region. The layers of increased conductivity were indicated at depths of $10 \mathrm{~km}, 35 \mathrm{~km}$ and $250 \mathrm{~km}$.

5. Results from the permanent observatory at Budkov represent soundings cristallinic non-conductive block with an increased penetration depth of the electromagnetic field. In addition to the layers of increased conductivity at $25 \mathrm{~km}, 90 \mathrm{~km}$ and $150 \mathrm{~km}$ more layers at $350 \mathrm{~km}$ and $800 \mathrm{~km}$ may be identified.

To summarize we may suggest the following possible model for the Czechoslovak territory so far investigated :

In the Carpathian region there are indications for layers of increased conductivity at depths between $10-15 \mathrm{~km}, 35-40 \mathrm{~km}$ and $100-150 \mathrm{~km}$. Whether similar conditions are characteristic for the Czech Massif remains to be proved by future measurements. Results from $\stackrel{\vee}{S}$ and B support this suggestion by indicating similar depths as in the 
Carpathian region.

Unsolved remains the question which discontinuities within the Earth, previously known from seismological data, may be identified with the layers of increased conductivity. A possible suggestion is to identify the first layer of increased conductivity at 10$15 \mathrm{~km}$ with the Conrad discontinuity. The second laver at $35-40 \mathrm{~km}$ would then correspond to the MOHO-discontinuity. However, the preliminary estimates of DSS in this region suggest the $\mathrm{MOHO}$ between $25-35 \mathrm{~km}$ and consequently, the magnetotelluric depths seem to be overestimated, or, this layer does not correspond to $\mathrm{MOHO}$ at all. The layer may be even fictitious and caused by the effect of the anisotropy. This conclusion may be derived from the theoretical investigation of the multilayer apparent resistivity curves for an anisotropic layered model [8].

The conductive layer in the upper mantle between $100-150 \mathrm{~km}$ corresponds fairly well to the estimates for the depths of the LVL in south-eastern Europe [9].

\section{References}

V. Petr, J. Pěčová, O. Praus : A Study of the Electric Conductivity of the Earth's Mantle by Magnetotelluric Measurement at Srobárová (Czechoslovakia). Travaux Inst. Géophys. Acad. Tchécosl. Sci. No. 208, Geofysikální sborník 1964, NČSAV 1965.

O. Praus, J. Pěčová, V. Petr and M. Tobyášová : The Depth Distribution of Electric Conductivity and Its Anisotropy according to Magnetotelluric Measurements at the Station Gabčíkovo (Czechoslovakia). Travaux Inst. Géophys. Acad. Tchécosl. Sci. No. 259, Geofysikální sborník 1966, NČSAV 1967.

J. Pěčová, O. Praus, M. Tobyášová: A Study of the Electric Conductivity of the Earth's Mantle from Magnetotelluric Measurements of the Budkov (Czechoslovakia) Station. Studia geoph. et geodet., 10 (1966), 185.

V. Petr. J. Pěčová, O. Praus, M. Tobyášová, M. Hvoždara : Anisotropy and Horizontal Inhomogeneity of Electrical Conductivity Derived from the Analysis of the Magnetotelluric Field at Srobárová (Czechoslovakia). Travaux Inst. Géophys. Acad. Tchécosl. Sci. No. 283, Geofysikální sborník 1967, NĆSAV 1968.

J. Pěčová, V. Petr, O. Praus, M. Tobyášová : Magnetotelluric Deep Sounding at Field Stations Nitrianská Blatnica, Nadrlenisko (Prievaly) and Pánov (Hodonín), Czechoslovakia Travaux Inst. Géo. phys. Acad. Tchécosl. Sci. (at press).

I. I. Rokityanski : On the Application of the Magnetotelluric Method to Anisotropic and Inhomogeneous Masses. Bulletin, Academy of Sci., USSR, Geophys. Series 11 (1961), 1607.

H. Wiese : Geomagnetische Induktionspfeile in der CSSR, hervorgerufen durch grossräuminge elektrische Leitfähigkeit-strukturen. Studia geoph. et geodet., 9 (1965), 415.

O. Praus and V. Petr: Magnetotelluric Calculations for the Interaction of Polarized Fields with Anisotropic Layered Media. Canadian Journal of Earth Sciences, 6, (1969), 759.

J. Vaněk : Amplitude Curves of Seismic Body Waves. Studia geophys. et geodet., 11 (19677), 335. 